Revista de Ciencias Sociales - Número 62 (2013) - Páginas 13-37

El contenido esencial de los derechos fundamentales: la libre iniciativa...

\title{
EL CONTENIDO ESENCIAL DE LOS DERECHOS FUNDAMENTALES: LA LIBRE INICIATIVA ECONÓMICA EN ESPAÑA Y CHILE
}

\author{
THE ESSENTIAL CONTENT OF HUMAN RIGHTS: \\ THE FREEDOM OF ECONOMIC INITIATIVE \\ IN SPAIN AND CHILE
}

\author{
CHRISTIAN VIERA ÁLVAREZ* \\ Universidad Viña del Mar \\ christian.viera@uvm.cl
}

\section{Resumen}

Distintas visiones existen sobre la determinación y existencia del contenido esencial de los derechos fundamentales. Se trata de un problema no resuelto que puede ser discutido y analizado en clave de apertura y diálogo. Por lo mismo, se presentan las dificultades sobre el contenido esencial en relación a la libre iniciativa económica, tanto del derecho español como chileno y una propuesta de su determinación.

Palabras claves

Constitución, contenido esencial, proporcionalidad.

\footnotetext{
* Abogado. Doctor en Derecho por la Universidad de Deusto (Bizkaia). Profesor de Derecho Constitucional. Artículo recibido el 1 de julio de 2013 y aceptado el 26 de julio de 2013.
}

Revista de Ciencias Sociales - Número 62 (2013) - Universidad de Valparáíso - ISSN 0716-7725-Valparáiso, Chile 


\section{Abstract}

Different views exist on the determination and existence of the essential content of fundamental rights. This is an unresolved issue that can be discussed and analyzed in the key of openness and dialogue. In the same way, it presents dificulties on the substantive content relating to economic freedom, both spanish and chilean law and a proposal for its determination.

\section{Keys words}

Constitution, essential content, proportionality.

\section{Introducción: El problema de la delimitación del contenido esencial}

Tratar sobre el contenido esencial de un derecho fundamental no es cosa fácil. Por un lado, se presenta el anhelo de encontrar una esfera irreductible que trascienda las categorías de tiempo y espacio, pero por otro, también se impone la realidad que muestra que los derechos siempre pueden modificarse y limitarse. Tan es así, que echando un vistazo a la historia es posible advertir que la comprensión que se ha tenido sobre ellos no es la misma ayer que hoy y, baste pensar en uno concreto para verificar la mutación que ellos sufren.

Sin embargo, a pesar de las mutaciones históricas, ¿queda un espacio indisponible? ¿Es la esencia de los derechos una categoría supra espacio/temporal? Eso es lo que trataremos de analizar y en específico, el caso de la libertad de empresa.

La cláusula 'contenido esencial' es ejemplo paradigmático de cláusula abierta y, la determinación de su contenido ha sido analizado por la doctrina desde diversas perspectivas, principalmente con una corriente absoluta y otra relativa.

En una temprana sentencia de 1981 el Tribunal Constitucional español abordó esta cuestión, declarando que constituye el contenido esencial de un derecho "aquellas facultades o posibilidades de actuación necesarias para que el derecho sea recognoscible como pertinente al tipo descrito y sin las cuales deja de pertenecer a ese tipo... (y) todo ello referido al momento histórico de que en cada caso se trata y a las condiciones inherentes en las sociedades democráticas, cuando se trate de derechos constitucionales"'.

1. STC $11 / 1981$ de 8 de abril de 1981, FJ 8 , párrafo $1^{\circ}$.

Facultad de Derecho y Ciencias Sociales - Universidad de Valparaíso - Chile 
A pesar de lo rotundo de las palabras, poco podemos deducir de esta definición, porque, cuáles son aquellos elementos pertinentes que permiten reconocer al derecho como perteneciente a un tipo o cuáles son las condiciones que favorecen su comprensión. Dado que el problema no es de fácil análisis, urge detenerse, en un primer momento, en los enfoques generales acerca del contenido esencial de los derechos. Como es sabido, al interpretar esta cláusula pugnan dos posiciones: las teorías relativa y absoluta.

La primera identifica contenido esencial con la exigencia de justificación de una limitación: contenido esencial sería aquella parte del derecho que todavía queda en pie una vez que ha operado una limitación justificada o legítima². Alexy, para este caso, identifica el contenido esencial con lo que queda tras la ponderación, es decir, "las restricciones que son acordes con el principio de proporcionalidad no vulneran la garantía del contenido esencial aun cuando en el caso particular no dejen nada del derecho fundamental. La garantía del contenido esencial se reduce al principio de proporcionalidad"3.

Por su parte, el principio de proporcionalidad consta de tres elementos: el examen de la adecuación de la limitación al bien que mediante ella se quiere proteger; el examen de la lesión del derecho para el fin pretendido, al no existir una medida menos gravosa y la proporcionalidad estricta, que trata de valorar si la lesión es proporcionada al fin que con ella se pretende. En resumidas cuentas, el contenido esencial será respetado cuando se justifica razonablemente en la necesidad de preservar otros bienes constitucionalmente protegidos ${ }^{4}$.

2. Véase PRIETO SANCHÍS, Luis. "La limitación de los derechos fundamentales y la norma de clausura de sistema de libertades”. En: Derechos y libertades. Universidad Carlos III, No 8, 2000. Pág. 438.

3. Véase ALEXY, Robert: Teoría de los derechos fundamentales. Centro de Estudios Políticos y Constitucionales, $2^{\text {a }}$ edición, Madrid, 2007. Pág. 259.

4. Véase MARTÍNEZ - PUJALTE, Antonio Luis. La garantía del contenido esencial de los derechos fundamentales, Centro de Estudios Constitucionales, Madrid, 1997. Págs. 21-22.

Revista de Ciencias Sociales - Número 62 (2013) - Universidad de Valparáíso - ISSN 0716-7725-Valparaíso, Chile 
La segunda, la teoría absoluta, sostiene la existencia de un núcleo resistente que debe ser preservado en todo caso: contenido esencial sería una parte del contenido del derecho al margen de cualquier negociación o debate ${ }^{5}$.

Tratándose de las teorías absolutas, no existe una sola postura, pero es característica en ellas la distinción para cada derecho de dos

Para el principio de proporcionalidad, y sin que la lista de obras sea exhaustiva, Véase SARMIENTO RAMÍREZ-ESCUDERO, Daniel. El principio de proporcionalidad en el derecho administrativo: un análisis jurídico desde el derecho español, Universidad Externado de Colombia, Bogotá, 2007; CARBONELL, Miguel (coord.). El principio de proporcionalidad en el Estado constitucional, Universidad Externado de Colombia, Bogotá, 2007; GONZÁLEZ BEILFUSS, Mónica. El principio de proporcionalidad en la jurisprudencia del Tribunal Constitucional, Thomson-Aranzadi, Navarra, 2003; FERNÁNDEZ NIETO, Josefa. Principio de proporcionalidad y derechos fundamentales: una perspectiva desde el derecho público común europeo, Editorial Dykinson, Madrid, 2008; BERNAL PULIDO, Carlos. El principio de proporcionalidad $y$ los derechos fundamentales: el principio de proporcionalidad como criterio para determinar el contenido de los derechos fundamentales vinculante para el legislador, Centro de Estudios Políticos y Constitucionales, Madrid, 2007; TERRADILLOS ORMAETXEA, Edurne. Principio de proporcionalidad, constitución y derecho del trabajo, Tirant lo Blanch, Valencia, 2004; VIDAL FUEYO, Camino. "El principio de proporcionalidad como parámetro de constitucionalidad de la actividad del juez". En: Anuario de Derecho Constitucional Latinoamericano, Tomo II, año 11, Fundación Konrad Adenauer Stiftung, 2005. Págs. 427-447.

5. Véase PRIETO SANCHÍS, Luis. Ob. Cit. Pág. 438; ALEXY, Robert. Ob. Cit.

Pág. 259. El mismo Prieto dice que "la tesis de la ilimitabilidad de los derechos pretende ofrecer una estrategia interpretativa simplificadora de los problemas que tradicionalmente ha planteado la limitación de los derechos y, en particular, también una fórmula para cercenar el margen de discrecionalidad judicial que permite la técnica de la ponderación de bienes. La idea central consiste en sustituir el debate sobre los límites por una definición precisa de los contenidos constitucionalmente protegidos: en lugar de decir, por ejemplo, que una ley limita la libertad religiosa en nombre del orden público o la de expresión en nombre del derecho al honor, se viene a sostener que tales interferencias en las conductas de los ciudadanos son en realidad 'externas' o 'ajenas' al contenido de la libertad tutelada; sencillamente porque ésta, en su tipificación constitucional, ya hizo del orden público o del honor un límite intrínseco, una frontera definitoria de su propio ser constitucional; de manera que allí donde la ley restrictiva aparece cabría decir que limita la 'libertad natural', pero no la 'libertad jurídica', cuyos contornos aparecen definidos por las conocidas cláusulas del orden público, del derecho al honor, etc.” (PRIETO SANCHÍS, Luis. Ob. Cit. Pág. 433).

Facultad de Derecho y Ciencias Sociales - Universidad de Valparaíso - Chile 
partes: un núcleo y una parte accesoria. Tratándose del núcleo, las limitaciones no son posibles porque se trata del contenido esencial, permitiéndose las restricciones en el anillo exterior o accesorio, siempre y cuando éstas no sean arbitrarias ${ }^{6}$.

Ahora bien, el problema que presenta la cláusula es que no se trata sólo de un concepto indeterminado, sino que también puede llegar a ser un concepto impredecible, en el sentido que parece imposible suministrar criterios mínimamente orientativos para delimitar en abstracto lo esencial que tiene un derecho fundamental. Si esto es así, sólo en el momento del concreto juicio por un Tribunal se podrá determinar si aquello que se presenta como derecho sigue siendo reconocible como tal a la luz del significado constitucional del tipo iusfundamental en cuestión ${ }^{7}$.

En todo caso, parece que es mayoritaria la doctrina y jurisprudencia que acoge la concepción relativa ${ }^{8}$, especialmente porque se trata de una teoría más realista, honesta y convincente justificar el no otorgamiento de protección a un derecho fundamental aduciendo que a ello se oponen derechos fundamentales de terceros o intereses de la comunidad que deben ser tomados en cuenta, que cuando se afirma que no se protege la conducta de que se trate porque no forma parte del derecho9. Con todo, es necesario señalar que, según ha señalado Alexy, el Tribunal Constitucional alemán, al parecer, sostiene la teoría absoluta,

6. Véase MARTÍNEZ - PUJALTE, Antonio Luis. Ob. Cit. Págs. 22-23.

7. Véase PRIETO SANCHÍS, Luis. Ob. Cit. Pág. 439.

8. Véase PAZ - ARES, Cándido-ALFARO ÁGUILA REAL, Jesús: "Derecho a la libertad de empresa y sus límites. La defensa de la productividad de acuerdo con las exigencias de la economía general y de la planificación”. En: MONEREO PÉREZ, José Luis et al (dirs.), Comentario a la Constitución socio-económica de España, Comares Editorial, Granada, 2002. Pág. 398.

Prieto cree que el TC ha hecho un uso prudente de la idea de contenido esencial y, lejos de enarbolarlo como un criterio autónomo y absoluto de control de la ley, parece haber observado una tendencia relativizadora, identificándolo con aquella parte del derecho que no se puede sacrificar legítimamente o con justificación suficiente (Véase PRIETO SANCHÍS, Luis. Ob. Cit. Pág. 440).

9. Véase ALEXY, Robert. Ob. Cit. Págs. 284-285.

Revista de Ciencias Sociales - Número 62 (2013) - Universidad de Valparáíso - ISSN 0716-7725-Valparaíso, Chile 
sin embargo, se trata de una posición que no es definitiva toda vez que existen sentencias contradictorias que permitirían sostener que más bien lo sostenido por el Tribunal es la teoría relativa ${ }^{10}$.

Con todo, a pesar de lo seductora que resulta la teoría relativa, no es menos cierto el peligro que encierra, puesto que después de aplicar el principio de proporcionalidad, puede ocurrir que tras ello no quede nada y pueda suponer el vaciamiento del derecho. Pero la absoluta también supone riesgos, ya que puede propiciar una disminución del nivel de garantías pues si se entendiera que, respetado el contenido esencial, la ley puede operar libremente en la esfera del derecho considerada como no esencial, resultaría que toda ley limitadora del 'contenido adjetivo' debería reputarse legítima, aun cuando fuese arbitraria o no justificada ${ }^{11}$.

\section{El contenido esencial de la libertad de empresa en el derecho español}

Veamos qué resulta de esta polémica para el caso de la libertad de empresa en el derecho español.

Si la cláusula 'contenido esencial' es de difícil determinación para los derechos fundamentales, no es distinto el panorama tratándose de este derecho y también colisionan las teorías absoluta y relativa.

Una consideración previa. La reflexión sobre el contenido esencial de un derecho fundamental supone un análisis de la razonabilidad de sus límites, es decir, revisar si hay un espacio sujeto a limitación, o si éstos son pertinentes, cuáles son las condiciones que lo permiten. Y esa dialéctica se presenta en el caso de la libertad de empresa, habida cuenta del importante rol que cabe al Estado como agente económico.

Por un lado, se encuentran aquellos que defienden para la libertad de empresa un contenido irreductible, inmune a toda limitación. Se reconoce que es tarea difícil, pero no renuncian a presentar un contenido absoluto para la libertad de empresa. En esta situación

10. Sobre este punto, véase ALEXY, Robert. Ob. Cit. Págs. 259-262.

11. Véase PRIETO SANCHÍS, Luis. Ob. Cit. Pág. 438.

Facultad de Derecho y Ciencias Sociales - Universidad de Valparaíso - Chile 
aparecen Rubio Llorente ${ }^{12}$, Aragón Reyes ${ }^{13}$ y Arroyo Jiménez.

En el caso de ARROYo JiMÉNEZ, expresamente se adscribe a la teoría absoluta $^{14}$, sin embargo, se muestra crítico con otras posiciones absolutas. Identifica el contenido esencial del derecho a la libertad de empresa con el mandato dirigido a los poderes públicos de reconocer el marco

12. Véase RUBIO LLORENTE, Francisco. "La libertad de empresa en la Constitución”, En: IGLESIAS PRADA, José Luis (coord.), Estudios jurídicos en homenaje al profesor Aurelio Menéndez, tomo I, Editorial Civitas, Madrid, 1996. Págs. 440-445. Este autor, ante la dificultad de fijar un contenido esencial para la libertad de empresa asocia este derecho a la igualdad: "la libertad de empresa conlleva así, asociada con la unidad del mercado, una particular aplicación del principio de igualdad, la necesidad de que todas las empresas disfruten del mismo grado de libertad en razón de la clase a la que pertenecen. No que todas las empresas tengan el mismo grado de libertad, pero sí que ésta sea igual para todas las que se dedican al mismo género de actividad, de manera que todas ellas sean jurídicamente iguales en el mercado" (Pág. 445).

Esta posición ha sido muy criticada, principalmente porque resta autonomía a la libertad de empresa, reduciéndolo a la igualdad. Véase ARROYO JIMÉNEZ, Luis. Libre empresa y títulos habilitantes, Centro de Estudios Políticos y Constitucionales, Madrid, 2004, p. 154; ARAGÓN REYES, Manuel. Libertades económicas y estado social, MacGraw-Hill, Madrid, 1995. Págs. 21-25; PAZ - ARES, Cándido-ALFARO ÁGUILA REAL, Jesús. Ob. Cit. Pág. 395.

13. Aragón proporciona algunos elementos para determinar el contenido esencial.

Parte de la distinción entre la facultad de iniciar, desarrollar y abandonar una actividad empresarial y frente a cada una de ellas señala un reducto infranqueable: "en cuanto al acceso, el reducto de libertad infranqueable probablemente es mínimo: no prohibición absoluta y no imposición forzosa. En cuanto al abandono, también ese reducto sería mínimo: no imposición de continuar. En cuanto al ejercicio, el ámbito absoluto de libertad sería mayor: el empresario ha de gozar de un mínimo, pero suficiente, reducto infranqueable de autonomía en la dirección de su empresa, sin la cual no sería empresa privada sino pública” (ARAGÓN REYES, Manuel. Ob. Cit. Pág. 33). Al parecer, la STC 225/1993, de 8 de julio de 1993, FJ 3 letra b es de esta opinión.

Las críticas a esta opinión apuntan a la dificultad en la determinación de los mínimos de esencialidad, dado que en función del tipo de actividad, hasta la más intensa de las injerencias puede resultar legítima (Véase ARROYO JIMÉNEZ, Luis. Ob. Cit. Págs. 156-157; PAZ - ARES, Cándido-ALFARO ÁGUILA REAL, Jesús. Ob. Cit. Pág. 394.

14. Véase ARROYO JIMÉNEZ, Luis. Ob. Cit. Pág. 119.

Revista de Ciencias Sociales - Número 62 (2013) - Universidad de Valparáíso - ISSN 0716-7725-Valparaíso, Chile 
de la economía de mercado, de modo que su contenido esencial "se concreta en el derecho individual a afrontar libremente aquellas actividades económicas cuya configuración como actividades de titularidad o de estricta regulación públicas, por implicar una transformación del modelo económico constitucional, resultaría contrario al contenido esencial" 15 .

Claro está, libertad de empresa no puede entenderse sin mercado, por lo que identificar el contenido esencial de este derecho con el mantenimiento de la economía de mercado y la imposibilidad de un cambio de modelo económico, es aportar muy poco, porque la misma institucionalización del mercado en la Constitución española implica la imposibilidad de su mutación. Tal vez, en un anhelo por defender la teoría absoluta, este autor se empeña por encontrar un reducto intocable, sin embargo, apostar por el respeto al modelo económico de mercado es insuficiente como contenido esencial de la libertad de empresa, habida consideración que el instituto 'mercado' ya está protegido constitucionalmente.

A mí entender, a pesar del notable esfuerzo que realizan los autores por encontrar un espacio intocable para la libertad de empresa, se podría sostener que la respuesta adecuada a esta cuestión está dada por la propuesta de la teoría relativa.

Como señalan PAZ - ARES y Alfaro, parece inútil el esfuerzo por tratar de delimitar el contenido esencial de la libertad de empresa. "La desazón proviene del hecho de que, por mucho que reduzcamos el contenido de la libertad de empresa, siempre puede haber razones que legitimen al legislador para no respetar ni siquiera ese ámbito"16.

Por ello la teoría de la proporcionalidad es una respuesta adecuada a esta problemática; la proporcionalidad exige el cumplimiento de tres condiciones: que la medida sea necesaria, adecuada y proporcionada. Hecho ese análisis y cumplidas las condiciones, en ese momento, y atendido el caso concreto, podría estimarse que la norma legal es constitucional porque respeta el contenido esencial de la libertad de empresa.

15. Ídem. Pág. 157.

16. PAZ - ARES, Cándido-ALFARO ÁGUILA REAL, Jesús. Ob. Cit. Pág. 394.

Facultad de Derecho y Ciencias Sociales - Universidad de Valparaíso - Chile 
La libertad de empresa es un derecho de textura abierta, porque debe compaginar la apertura económica con el hecho que España se constituye en un Estado social, cláusula que respalda la idea de que el contenido de las libertades económicas viene delimitado por la función social de estos derechos, lo que supone límites y deberes de carácter positivo $^{17}$.

Asimismo, lo particular de la libertad de empresa es que el constituyente habría delimitado el derecho no por referencia a intereses o derechos concretos, sino mediante la remisión a cláusulas como 'interés general', 'exigencias de la economía general' o la 'planificación', por lo que para limitar este derecho se encuentra el recurso a las cláusulas generales y sociales. A fin de cuentas, la gran mayoría de las tareas que justifican la calificación del Estado como social otorgan títulos de intervención en la actividad económica privada ${ }^{18}$.

Con todo, estableciendo condiciones al ejercicio de la iniciativa económica, el Estado debe tratar de arbitrar soluciones a los posibles conflictos entre normas constitucionales, entre los que destaca la ponderación de intereses relevantes y el cuidado normativo en la configuración del ámbito de aplicación ${ }^{19}$.

Por lo mismo, si la libertad de empresa es un derecho fundamental como cualquier otro, la ponderación que deben realizar los intérpretes

17. Y así la ha afirmado el TC en un caso en que se relacionan derecho de propiedad y libertad de empresa: STC 37/1987, de 26 de marzo de 1987: “desde el punto de vista de lo que prescribe el art. 38 de la Constitución, la función social de la propiedad, al configurar el contenido de este derecho mediante la imposición de deberes positivos a su titular..." (FJ 5, párrafo $8^{\circ}$. Cursivas son mías); "(la) libertad de empresa que reconoce el art. 38 de la Constitución no puede exonerar del cumplimiento de la función social de la propiedad, de lo que se sigue que las limitaciones legítimamente derivadas de esta última no infringen en ningún caso el contenido esencial de la libertad de empresa” (FJ 5, último párrafo).

18. Véase PAZ - ARES, Cándido-ALFARO ÁGUILA REAL, Jesús. Ob. Cit. Págs. 399-400.

19. Véase GARCÍA VITORIA, Ignacio. La libertad de empresa: ¿un terrible derecho?, Centro de Estudios Políticos y Constitucionales, Madrid, 2008. Pág. 195.

Revista de Ciencias Sociales - Número 62 (2013) - Universidad de Valparáíso - ISSN 0716-7725-Valparaíso, Chile 
exige el cumplimiento de todos y cada uno de los pasos que supone la aplicación del principio de proporcionalidad. Ahora bien, la complejidad del mundo económico impide dar soluciones a priori sobre los resultados de la ponderación, ya que la regulación de los diferentes sectores de la economía no es simétrica; hay espacios en que la intervención del Estado es muy amplia y otras en que es reducida, v.g. no revisten el mismo grado de intensidad la intervención estatal en materia medioambiental o en el sector de telecomunicaciones que en el comercio minorista.

Por tanto, siendo el mercado el marco para el desarrollo de la iniciativa privada, contenido esencial de la libertad de empresa será el resultado de la ponderación de las medidas restrictivas, que deben cumplir las exigencias del principio de proporcionalidad: necesidad, adecuación, proporcionalidad y, como señala Alexy, que el fin perseguido debe ser digno de la limitación del derecho fundamental por tratarse de intereses que tienen el mismo rango abstracto ${ }^{20}$.

\section{El respeto al contenido esencial en el derecho chileno}

Esta garantía de protección de los derechos fundamentales fue analizada en el punto 1 de este trabajo y me remito a él en lo relativo a la dificultad que supone la determinación del contenido esencial y las diversas teorías que existen al respecto. En esta sección simplemente me limitaré a analizar lo que ocurre en la Constitución chilena respecto de esta materia y las opiniones doctrinales y jurisprudenciales sobre la misma.

Dice el art. $19 \mathrm{~N}^{\circ} 26$ que la Constitución asegura a todas las personas "la seguridad de que los preceptos legales que por mandato de la Constitución regulen o complementen las garantías que esta establece o que las limiten en los casos en que ello lo autoriza, no podrán afectar los derechos en su esencia, ni imponer condiciones, tributos o requisitos que impidan su libre ejercicio". Según Nogueira, a esta norma se debe unir el art. 5 inc. 2 que señala que "la soberanía tiene como límite los derechos esenciales que emanan de la naturaleza humana", con lo cual, "el límite del contenido de los derechos se proyecta

20. Véase ALEXY, Robert. Ob. Cit. Pág. 72.

Facultad de Derecho y Ciencias Sociales - Universidad de Valparaíso - Chile 
no sólo al legislador, sino también al poder constituyente instituido, estableciendo una garantía de irreversibilidad en materia de derechos fundamentales, lo que nos sitúa en la materia, en una afirmación y garantía mayor de los derechos fundamentales que los tres países antes mencionados" ${ }^{21}$.

Ahora bien, tratándose del TC chileno, a propósito del control de constitucionalidad respecto de la Ley de partidos políticos, ha tenido ocasión de referirse al contenido esencial señalando que "un derecho es afectado en su 'esencia' cuando se le priva de aquello que le es consustancial de manera tal que deja de ser reconocible y que se 'impide el libre ejercicio' en aquellos casos en que el legislador lo somete a exigencias que lo hacen irrealizable, lo entraban más allá de lo razonable o lo privan de tutela jurídica" 22 . Asimismo, agrega el TC que en el supuesto de establecer limitaciones a un derecho, éstas "jamás pueden afectar el contenido esencial, esto es, no pueden consistir en 'privación' del derecho, privación para la cual, en conformidad con la Constitución, no tiene competencia el legislador" ${ }^{23}$. Y esta privación que lo hace irrealizable o lo limita más allá de lo razonable, el TC la define así: "el derecho se hace impracticable cuando sus facultades no pueden ejecutarse. El derecho se dificulta más allá de lo razonable cuando las limitaciones se convierten en intolerables para su titular" ${ }^{24}$.

21. NOGUEIRA ALCALÁ, Humberto: “Aspectos de una Teoría de los Derechos Fundamentales: La Delimitación, Regulación, Garantías y Limitaciones de los Derechos Fundamentales”. En: Ius et Praxis, Universidad de Talca, vol.11, № 2. Págs. 15-64. Por lo mismo, señala el autor que "el legislador está obligado a respetar y tiene prohibido constitucionalmente afectar el contenido esencial de los derechos. Dicho contenido esencial se constituye en la barrera constitucional insuperable e infranqueable en la tarea de establecer posibles limitaciones de los derechos, constituye un límite al poder de limitar los derechos, constituyendo la dimensión constitucional del derecho proveniente de la tradición jurídica que se debe preservar" (Ídem. Pág. 49).

22. STCCh rol 43, 24 de febrero de 1987 , considerando $21^{\circ}$. La misma referencia es recogida en las SSTCCh, rol 200, 14 de diciembre de 1994, considerando $5^{\circ}$; rol 280, 20 de octubre de 1998, considerandos $13^{\circ}$ y $29^{\circ}$.

23. STCCh, rol 226, de 30 de octubre de 1995, considerando $46^{\circ}$.

24. STCCh, rol 280, 20 de octubre de 1998, considerando $29^{\circ}$.

Revista de Ciencias Sociales - Número 62 (2013) - Universidad de Valparáíso - ISSN 0716-7725-Valparaíso, Chile 
Aun cuando el TC chileno abraza la teoría absoluta para interpretar el contenido esencial, de todas maneras se encarga de acoger criterios de apertura para la comprensión del contenido esencial de los derechos: "estos supuestos deben ser aplicados, en todo caso, con la confluencia de dos elementos irrenunciables. En primer lugar, el momento histórico de cada situación concreta, por el carácter evolutivo del contenido esencial del derecho; y luego, las condiciones inherentes de las sociedades democráticas, lo que alude a determinar el sistema de límites del ordenamiento jurídico general y cómo juega en ella el derecho y la limitación"25.

Con todo, a pesar de los esfuerzos del TC por establecer pautas de determinación en una materia polémica, los suyos no dejan de ser criterios imperativos y autoritarios, que no cuentan con un análisis dialéctico, porque se trata de afirmaciones más categóricas que sintéticas.

Realizando un esfuerzo por dotar de significado al contenido esencial, Noguerra sostiene que éste debe ser inferido del sistema coordinado y armonizado del todo constitucional, puesto que "no hay parámetro objetivo alguno que permita precisar que es esencial y que es periférico en un derecho fundamental" 26 , pero agregando que "el núcleo del derecho está delimitado y constituido por los enunciados normativos constitucionales y de los tratados sobre la materia... Así, el concepto de contenido esencial de los derechos, está dado por la complementación indisoluble del valor fundamental y supremo de la dignidad humana con el núcleo básico e intrínseco de cada derecho fundamental, expresado en forma jurídico-positiva y garantizado por la Constitución”"27.

25. Ídem, considerando 29, párrafo final.

26. NOGUEIRA ALCALÁ, Humberto. Ob. Cit. Pág. 58. Para la determinación del contenido esencial del derecho, este autor señala que "está constituido por el tratamiento que la Constitución y los tratados sobre derechos humanos efectúan sobre los derechos en su articulado, sin que los tratados puedan rebajar las garantías del contenido ya establecido constitucionalmente, sino que sólo operando como normativa que enriquece, potencializa y garantiza mejor los derechos, vale decir, aplicando el principio de progresividad e irreversibilidad en materia de derechos complementado con el principio 'favor homine' o ‘favor persona”' (Ídem. Pág. 58).

27. NOGUEIRA ALCALÁ, Humberto. Ob. Cit. Pág. 58.

Facultad de Derecho y Ciencias Sociales - Universidad de Valparaíso - Chile 
$\mathrm{Al}$ mismo tiempo, NogueIRA se pregunta acerca del rol que en la interpretación del contenido esencial corresponde al TC y a los Tribunales de Justicia, señalando que a éstos, al no ser órganos constituyentes, sólo les cabe interpretar y aplicar la normativa constitucional $^{28}$.

Por último, Nogueira une la limitación del contenido esencial con el principio de razonabilidad y proporcionalidad de los límites, con lo cual podríamos pensar que este autor defiende la teoría relativa, lo que no es cierto ya que se muestra distante de ella por el peligro de relativización ${ }^{29}$.

Me he detenido en Nogueira porque se trata de un autor que ha desarrollado un tema que raramente ha sido analizado en Chile ${ }^{30}$. Sin embargo, sus consideraciones merecen algunas observaciones.

28. Véase NOGUEIRA ALCALÁ, Humberto. Ob. Cit. Pág. 58. En efecto, señala que "es necesario preguntarse si dicha tarea corresponde también al Tribunal Constitucional y a los tribunales superiores de justicia, en cuanto órganos jurisdiccionales encargados de ejercer jurisdicción o justicia constitucional. Consideramos que los órganos jurisdiccionales señalados no son órganos constituyentes, sino que órganos instituidos, los cuales deben respetar en cuanto tales la Carta Fundamental, a ellos sólo les corresponde interpretar y aplicar la normativa constitucional” (Ídem. Pág. 59).

29. "el contenido esencial de los derechos fundamentales no opera como único límite de los límites, existiendo un segundo que opera copulativamente con el primero, el cual consiste en la exigencia de que la limitación del ejercicio del derecho se encuentra justificada. En otras palabras, un derecho fundamental sólo puede ser objeto de limitación válida desde un juicio de constitucionalidad si está justificada constitucionalmente a través del juicio de razonabilidad y proporcionalidad y si no afecta el contenido esencial de los derechos. Hay así una prohibición de desproporción, las leyes que limitan el ejercicio de los derechos y garantías deben restringirse a lo indispensable no afectando el los derechos constitucionalmente protegidos. Toda intervención estatal en el ámbito del ejercicio de los derechos fundamentales debe tener un sentido de proporcionalidad entre los medios empleados y los objetivos perseguidos que se deriva de la naturaleza de los derechos humanos y del Estado de Derecho" (Ídem. Pág. 59).

30. Del mismo autor, véase NOGUEIRA ALCALÁ, Humberto: "Los derechos económicos, sociales y culturales como derechos fundamentales efectivos en el constitucionalismo democrático latinoamericano”. En: Estudios Constitucionales,

Revista de Ciencias Sociales - Número 62 (2013) - Universidad de Valparáíso - ISSN 0716-7725-Valparaíso, Chile 
La primera, su confianza excesiva en la normatividad, entendiendo que el contenido esencial es el que aparece en la Constitución y en las normas sobre derechos fundamentales, principalmente los tratados internacionales.

A primera vista se trata de un criterio a considerar. Sin embargo, el reconocimiento de los derechos fundamentales en los tratados muchas veces revisten el carácter de cláusulas abiertas, por lo tanto de contenido indeterminado y condicionados por su contexto. En todo caso, sí resulta relevante y destacable la propuesta de integrar la comprensión del contenido esencial con el carácter progresivo de los derechos fundamentales y el criterio favor homine. No obstante, estas creaciones jurídicas, que han favorecido un mayor y mejor respeto y promoción de los derechos fundamentales, cuenta con el inconveniente de toda construcción cultural: no pueden escapar a las condiciones de tiempo y espacio y exigen confiar en la madurez política de la sociedad para que no disminuya la garantía que suponen para la protección y promoción de los derechos.

La segunda, señala que los órganos jurisdiccionales son operadores que sólo deben 'interpretar' y aplicar la Constitución y las leyes, pero no dotar de contenido a los derechos. Sin embargo, la praxis demuestra que será el intérprete el encargado de ir determinando el contenido esencial de los derechos, ya que éste va mudando, tanto por el transcurso del tiempo como por su relación (y tensión) con otros derechos. Por tanto, a los órganos jurisdiccionales, y especialmente al TC les cabe un importante rol en la determinación del contenido

Centro de Estudios Constitucionales, año 7, № 2, 2009, Págs. 172-174. También puede verse, pero se trata de obras que revisan el tema de forma muy genérica: CEA EGAÑA, José Luis: "La esencia de los derechos y su libre ejercicio". En: Revista de Derecho Público, No 29-30, Universidad de Chile, 1981. Págs. 112-117; RAJEVIC MOSLER, Enrique: "Limitaciones, reserva legal y contenido esencial de la propiedad privada". En: Revista chilena de Derecho, Pontificia Universidad Católica de Chile, vol. 23, No 1, 1996. Págs. 40-44; FERMANDOIS VÖHRINGER, Arturo: "La reserva legal: una garantía sustantiva que desaparece”. En: Revista chilena de Derecho, Pontificia Universidad Católica de Chile, vol. 28, No 2. Págs. 295-296; SOTO KLOSS, Eduardo: "La actividad económica en la Constitución Política de la República de Chile (La primacía de la persona humana)”. En: Ius Publicum, Universidad Santo Tomás, No 2, 1999. Pág. 128.

Facultad de Derecho y Ciencias Sociales - Universidad de Valparaíso - Chile 
esencial, como legítimos intérpretes de la Carta Fundamental. Otra cosa es la relativa a la legitimidad democrática de su composición, pero no podemos negarle la importancia que les cabe en la materia.

El tema del contenido esencial puede suponer una discusión abstracta, no obstante, se trata de un problema que tiene incidencia operativa, especialmente porque se utiliza especialmente con vistas a resistir las limitaciones que se puedan establecer a un derecho. Veamos algunos ejemplos.

Con ocasión del examen de constitucionalidad de la Ley de Prensa, algunas de sus disposiciones fueron declaradas contrarias a la Constitución. En el caso del inc. 2 del art. 43 del proyecto de ley, éste fue rechazado por el TC, letras a) y b) por violar, el art. $19 \mathrm{~N}^{\circ} 21$ (libertad de empresa), pero también el art. $19 \mathrm{~N}^{\circ} 26$ (respeto al contenido esencial) ${ }^{31}$, sin perjuicio de adolecer también de vicios desde la perspectiva de la formación de la ley.

Señala como razones de inconstitucionalidad que el referido art. 43, al establecer limitaciones al control de la propiedad de los medios, atenta contra el art. $19 \mathrm{n}^{\circ} 21$, es decir, "de desarrollar cualquiera actividad (económica) lícita sin más limitaciones que no ser contraria a la moral, ni al orden público ni a la seguridad nacional, puesto que ninguna de estas circunstancias se da aquí, ya que la actividad que se pretende impedir no aparece atentatoria a ellas porque se tengan porcentajes mayores a los que el proyecto prevé" 32 . Pero además, "la limitación que tanto la letra a) como la letra b) disponen en cuanto a la posesión de

31. Señalaba el inciso segundo del art. 43 del proyecto de ley que "se reputarán como hechos de la naturaleza de los sancionados en el inciso precedente: a) En el ámbito de la prensa escrita, el control de más del 30\% del mercado informativo nacional en manos de una persona natural o jurídica, sola o asociada con otra u otras; y el control directo o indirecto por una persona natural o jurídica, sola o asociada con otra u otras, de más del 30\% de la distribución de los diarios de información general; b) El control de más del $15 \%$ del mercado informativo general por una sola persona natural o jurídica; o más del $20 \%$ del referido mercado por dos o más personas naturales o jurídicas, asociadas; c) El dominio de dos o más tipos diversos de medios de comunicación social en un mismo mercado, por una persona natural o jurídica, sola o asociada con otra u otras”.

32. STCCh, rol 226, de 30 de octubre de 1995, considerando $44^{\circ}$.

Revista de Ciencias Sociales - Número 62 (2013) - Universidad de Valparaíso - ISSN 0716-7725-Valparaíso, Chile 
porcentajes llamado 'control' afectan de manera directa la posibilidad de desarrollar la actividad económica indicada, por causas ajenas a las que la Constitución precisa en su artículo $19, \mathrm{~N}^{\circ} 21$, inciso primero, imponiendo exigencias que afectan al contenido esencial de este derecho reconocido expresamente por el artículo $19, \mathrm{~N}^{\circ} 26$, pues impiden su libre ejercicio" ${ }^{33}$.

En este caso, el carácter garantista del respeto al contenido esencial fundamenta la sentencia. Pero su argumentación genera algunos inconvenientes.

El primero, es que afirma que las limitaciones establecidas por la ley no se encuentran comprendidas entre las autorizadas por la Constitución. Sin embargo, orden público, moral o seguridad nacional son cláusulas abiertas que deben interpretadas contextualmente y que justifican una limitación a la libre iniciativa económica ${ }^{34}$.

El segundo, afirma la sentencia que las limitaciones impuestas afectan el contenido esencial del art. $19 \mathrm{~N}^{\circ} 21$. iPero sin dar ni un solo argumento explicativo acerca del contenido esencial de la libertad de empresa! ¿Será porque se trata de una obviedad? ¿’ por qué es un tema pacífico? Nada más lejos de la realidad.

Es cierto que hay elementos que deben formar parte del derecho. Por de pronto, la libre iniciativa económica no puede entenderse sin mercado, que será su presupuesto fáctico. Y si el mercado es el marco de referencia, éste no se entiende sin competencia. De ahí entonces la contradicción de la sentencia, porque la disposición declarada inconstitucional, lo que pretendía era estimular la competencia y prohibir la concentración de los medios informativos en pocas manos

33. Ibíd., considerando $45^{\circ}$. La cursiva es mía.

34. Simplemente a modo de hipótesis, es razonable postular que el sistema de derechos fundamentales forma parte de la moral, ya que permite el la protección de la persona, pero también el despliegue legítimo de la pluralidad social en una sociedad democrática. ¿'O acaso la moralidad sólo está asociada a la moral sexual? Recordemos que también existen perspectivas morales y éticas relacionadas con el carácter social del ser humano. En este caso, el control de la propiedad por parte de unos pocos oligopolios atenta contra el derecho a la libertad de expresión, al no favorecer un modelo informativo plural.

Facultad de Derecho y Ciencias Sociales - Universidad de Valparaíso - Chile 
- el peligro del totalitarismo informativo no sólo es privilegio estatal; los particulares no están exentos de la tentación totalitaria- por lo que si existe un contenido esencial básico de la libertad de empresa, éste se encuentra dado por el marco del mercado y el supuesto de la competencia. Lo anterior no significa en todo caso claridad sobre la comprensión del contenido esencial, pero es un límite básico y primordial.

Finalmente, la libertad de empresa es un derecho de textura abierta y que cuenta con límites, que se han establecido no por referencia a intereses o derechos concretos, sino mediante la remisión a cláusulas generales, por lo que para limitar este derecho se encuentra el recurso a los conceptos jurídicos indeterminados.

Con todo, estableciendo condiciones al ejercicio de la iniciativa económica, el Estado debe esforzarse por arbitrar soluciones a los posibles conflictos entre normas constitucionales, por lo que resultará de capital importancia la ponderación de intereses relevantes y el cuidado normativo en la configuración de los diferentes espacios de aplicación de la normativa en la que influye la libre iniciativa económica. Por lo mismo, si la libre iniciativa económica es un derecho fundamental como cualquier otro, la ponderación que deben realizar los intérpretes exige el cumplimiento de todos y cada uno de los pasos que supone la aplicación del principio de proporcionalidad.

\section{Conclusión}

Por lo visto, polémica resulta una determinación sustantiva a la cláusula "contenido esencial", especialmente porque la pretensión inicial es establecer un espacio de radical inmutabilidad para los derechos fundamentales. Sin embargo, esa pretensión es problemática, porque los anhelos universalistas son difíciles de justificar sin caer en axiomas autoritarios. Como tantas cláusulas abiertas, se trata de una disposición contingente, evolutiva, histórica y condicionada por su contexto. Asimismo, siempre se pueden encontrar razones para limitar un derecho, limitaciones que responden y reclaman un contexto.

Si esto es así y no existe contenido esencial de los derechos, se produce el problema de la relativización de todos los derechos, ya que

Revista de Ciencias Sociales - Número 62 (2013) - Universidad de Valparáíso - ISSN 0716-7725-Valparaíso, Chile 
todos se pueden restringir. ¿Dónde están los límites entonces? Los límites estarán dados no por axiomas de autoridad sino que por los esfuerzos de la deliberación. Y en este punto, capital importancia le cabe a las propuestas metodológicas para construir acuerdos en la comunidad.

Por lo mismo, más que preocuparnos del contenido esencial de los derechos, los esfuerzos jurídicos y políticos deben estar encaminados a corregir y construir métodos que nos lleven a los acuerdos en materia de derechos fundamentales.

\section{Bibliografía}

ALEXY, Robert: Teoría de los derechos fundamentales. Centro de Estudios Políticos y Constitucionales, $2^{\text {a }}$ edición, Madrid, 2007.

ARAGÓN REYES, Manuel. Libertades económicas y estado social, MacGraw-Hill, Madrid, 1995.

ARROYO JIMÉNEZ, Luis. Libre empresa y títulos habilitantes, Centro de Estudios Políticos y Constitucionales, Madrid, 2004.

BERNAL PULIDO, Carlos. El principio de proporcionalidad y los derechos fundamentales: el principio de proporcionalidad como

criterio para determinar el contenido de los derechos fundamentales vinculante para el legislador, Centro de Estudios Políticos y Constitucionales, Madrid, 2007.

CARBONELL, Miguel (coord.). El principio de proporcionalidad en el Estado constitucional, Universidad Externado de Colombia, Bogotá, 2007.

CEA EGAÑA, José Luis: "La esencia de los derechos y su libre ejercicio". En: Revista de Derecho Público, No 29-30, Universidad de Chile, 1981. Págs. 112-117.

FERMANDOIS VÖHRINGER, Arturo: "La reserva legal: una garantía sustantiva que desaparece". En: Revista chilena de Derecho, Pontificia Universidad Católica de Chile, vol. 28, N 2. Págs. 287-298.

FERNÁNDEZ NIETO, Josefa. Principio de proporcionalidad y derechos fundamentales: una perspectiva desde el derecho público común europeo, Editorial Dykinson, Madrid, 2008.

Facultad de Derecho y Ciencias Sociales - Universidad de Valparaíso - Chile 
GARCÍA VITORIA, Ignacio. La libertad de empresa: ¿un terrible derecho?, Centro de Estudios Políticos y Constitucionales, Madrid, 2008.

GONZÁLEZ BEILFUSS, Mónica. El principio de proporcionalidad en la jurisprudencia del Tribunal Constitucional, Thomson Aranzadi, Navarra, 2003.

MARTÍNEZ - PUJALTE, Antonio Luis. La garantía del contenido esencial de los derechos fundamentales, Centro de Estudios Constitucionales, Madrid, 1997.

NOGUEIRA ALCALÁ, Humberto: "Aspectos de una Teoría de los Derechos Fundamentales: La Delimitación, Regulación, Garantías y Limitaciones de los Derechos Fundamentales”. En: Ius et Praxis, Universidad de Talca, vol.11, No 2. Págs. 15-64.

NOGUEIRA ALCALÁ, Humberto: "Los derechos económicos, sociales y culturales como derechos fundamentales efectivos en el constitucionalismo democrático latinoamericano". En: Estudios Constitucionales, Centro de Estudios Constitucionales, año 7, No 2, 2009. Págs. 403-466.

PAZ - ARES, Cándido-ALFARO ÁGUILA REAL, Jesús: "Derecho a la libertad de empresa y sus límites. La defensa de la productividad de acuerdo con las exigencias de la economía general y de la planificación”. En: MONEREO PÉREZ, José Luis et al (dir.), Comentario a la Constitución socio-económica de España, Comares Editorial, Granada, 2002. Pág. 398.

PRIETO SANCHÍS, Luis. "La limitación de los derechos fundamentales y la norma de clausura de sistema de libertades". En: Derechos y libertades. Universidad Carlos III, No 8, 2000. Págs. 429468.

RAJEVIC MOSLER, Enrique: "Limitaciones, reserva legal y contenido esencial de la propiedad privada”. En: Revista chilena de Derecho, Pontificia Universidad Católica de Chile, vol. 23, No 1, 1996. Págs. 2396.

RUBIO LLORENTE, Francisco. "La libertad de empresa en la Constitución”. En: IGLESIAS PRADA, José Luis (coord.), Estudios jurídicos en homenaje al profesor Aurelio Menéndez, tomo I, Editorial Civitas, Madrid, 1996. Págs. 427-447.

Revista de Ciencias Sociales - Número 62 (2013) - Universidad de Valparáíso - ISSN 0716-7725-Valparaíso, Chile 
SARMIENTO RAMÍREZ-ESCUDERO, Daniel. El principio de proporcionalidad en el derecho administrativo: un análisis jurídico desde el derecho español, Universidad Externado de Colombia, Bogotá, 2007.

SOTO KLOSS, Eduardo: "La actividad económica en la Constitución

Política de la República de Chile (La primacía de la persona humana)". En: Ius Publicum, Universidad Santo Tomás, No 2, 1999. Págs. 119-146.

TERRADILLOS ORMAETXEA, Edurne. Principio de proporcionalidad, constitución y derecho del trabajo, Tirant lo Blanch, Valencia, 2004.

VIDAL FUEYO, Camino. "El principio de proporcionalidad como parámetro de constitucionalidad de la actividad del juez". En: Anuario de Derecho Constitucional Latinoamericano, Tomo II, año 11, Fundación Konrad Adenauer-Stiftung, 2005. Págs. 427-447.

Facultad de Derecho y Ciencias Sociales - Universidad de Valparaíso - Chile 